\title{
Transanal endoscopic microsurgery: indications and results after 100 cases
}

\author{
P. Palma / S. Freudenberg / S. Samel / S. Post
}

\begin{abstract}
O bjective Transanal endoscopic microsurgery (TEM), a minimally invasive technique has been employed in the excision of benign and well-selected malignant rectal tumours since Jume 1998. We present a prospective descriptive study and analyse the currently accepted indications.

Patients and methods Over a 4-year period 100 patients underwent TEM for treatment of rectal tnmonrs located between 4 and $18 \mathrm{~cm}$ from the anal verge.

Results TEM was performed in 71 cases for adenomas, 20 potentially curative excisions for pre-operative staged lowgrade carcinoma, 3 palliative procedures for advance carcinoma, 5 carcinoids and I solitary ulcer. The local complication rate inchuded wonnd breakdown in 7 patients, three of them reqniring
\end{abstract}

\section{Introduction}

Colorectal cancer represent the second leading cause of cancer-related mortality in the Western world. It is widely accepted that the adenoma-carcinoma sequence represents the process by which most, if not all, rectal carcinomas arise [1]. The appropriate management of individuals with precursor adenomatous polyps in the ileostomy. Conversion to laparotomy was performed in two patients. Five adenomas recurred and were successfilly treated by TEM. Of the cancers, four patients required immediate salvage therapy by means of total mesorectal excision.

Three patients underwent palliative TEM procednres combiued with radiotherapy. A single cancer recurrence was treated by means of abdomino-perineal resection after radiotherapy.

Conclusions TEM appears to be an effective method of excising benign tmmonrs and selected $T I$ carcinomas of the rectum. The superior exposure of tumours higher in the rectum combined with the greater precision of excision make this minimally invasive technique an attractive surgical approach.

rectum, is removal by means of polypectomy with snare diathermy, or complete local resection depending on the size and morphology. Additionally, local resection is also indicated for selected 'lowrisk' rectal carcinomas. However tumour location may limit local removal per se lcading to more aggressive posterior approaches or to an anterior resection via laparotomy-laparoscopy.

Palabras clave: Transanal endoseopic microsurgery, rectal adenoma, rectal earcinoma, local excision.

Fecha de recepción: Enero 2004 . 
Transanal endoscopic microsurgery (TEM) was introduced by Buess et al. in 1984. [2] and is currently undergoing widespread evaluation for treatment of both arlenomas and selected carcinomas [3-10]. TEM is a minimally invasive method that allows precise resection of tumours located 4-18 cm from the anal verge using an operative rectoscope.

The aim of the present study was to report our single Institution experience. The major paramelers of the study ace the analysis of the currently accepted indications, as well as practicability, morbidity and recurrence rates of the method since its introduction in our coloproctology nuit.

\section{Materials and methods}

\section{Patients}

Between June 1998 and June 2002, all patients with rectal tumours were examined in our interdisciplinary surgical-endoscopy unit. Following clinical examination, a biopsy was obtained in all patients, and endorectal sonography was performed using a 360-degree endoprobe with an inflatable balloon at a frequency of 7.5 $\mathrm{MHz}$ for accurate pre-operative staging (Fig. 1). An abdominal ultrasound and a colonoscopy were also performed ill all patients in order to rule out synchronous more proximal pathology.

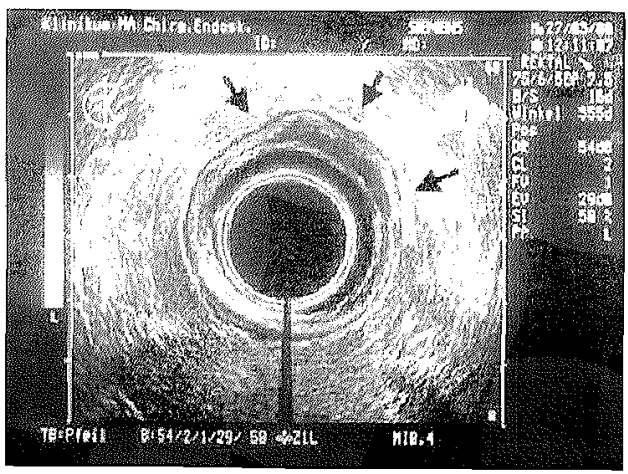

Figure 1.-Endorectal sonography showing a T1 rectal tumour.
Pre-operative staging resulted in three patient groups: The largest group in our experience had benign rectal tumours not suitable for removal by endoscopic diathermy snare. The second group had proven rectal cancer. The third and smallest group comprised neuroendocrine, carcinoid and miscellaneous tumours.

A total of 100 patients presenting with tumours located $4-18 \mathrm{~cm}$ from the anal verge were treated by TEM. No other surgical approach was used or evaluated for local excision in our department since the beginning of the study. Only three patients, presenting high risk features (lymplovascular or muscular invasion, or poor differentiation) were operated using TEM with a palliative intention. The bowel was prepared as for a formal laparotomy by lavage over $5 \mathrm{~h}$ with $3-4$ litres of polyethylene glycol solution. Antibiotic prophylaxis consisted of a single dose of a cephalosporin plus metronidazole and was given at the time of anaesthetic induction.

\section{Methods}

Following the original description by Buess et al. [2], we used an operative rectoscope of $4.0 \mathrm{~mm}$ diameter and 120 or $200 \mathrm{~mm}$ length, with a sixfold magnified stereoscopic view (Fig. 2). For better visualization, $\mathrm{CO} 2$ is insufflated to enlarge the intrarectal space and therefore facilitate dissection. This is combined with a nonstop suction

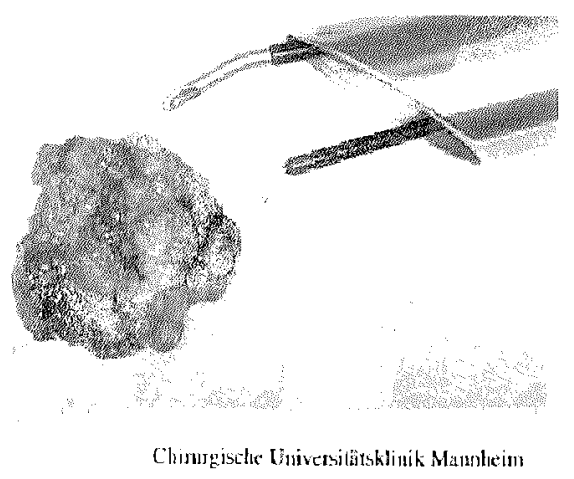

Figure 2.-Bluess TEM operative rectoscope with a resected adenoma. 
unit to ensure constant, ligh flow of gas and to evacuate the smoke due to coagulation. The operation itself was performed as described originally by Buess et al. [2].

Postoperatively, patients are allowed to sit and walk as soon as they have fully recovered from general anaesthesia. A liquid diet is maintained for $4.8 \mathrm{~h}$, and patients are discharged on postoperative day 4 after a clinical examination. Initial clinical follow-up occurs at three months postoperatively by means of clinical examination, endoscopy and endorectal ultrasound. A standard follow up occurs once a year for the following years.

Patient data were prospectively collected on a personal computer and managed using Microsoft Excel. Deseriptive statistics were used, and results are expressed as the absolute value, mean, standard deviation, range and percent.

\section{Results}

Over the 4-year period of study, 100 patients satisfied the indications for TEM and were included in the report. Of these 58 were male, and 42 female, with a median age of 63 years (range 35-91 ycars) (Table 1). Rectal blood loss was the leading symptom in 68 cases. All other patients presented with nonspecific symptoms. Two patients presented two synchronous reetal adenonas. Meau tumour location from the anal verge was $9.4 \pm 2.3 \mathrm{~cm}$ (range $4-18 \mathrm{cnr}$ ).

Tumonrs were classified in three groups according to the size of the rectal wall defect after resection. Group $1(n+25)$, when the defect was semicircular, group 2 $(n+56)$ includes defects representing a quarter of the circumference, and group 3 $(n+19)$ includes those tmmours with a defect up to $1.5 \mathrm{~cm}$.

Pre-operative endorectal sonography was performed in 97 cases. In only three the technique was not possible due to higl location. Sonography correctly staged the tumour in 96 cases. The case misclassified
Table 1. Patients and tumour characteristics

\begin{tabular}{|lll|}
\hline Characteristic & $n$ & Ranuge \\
\hline Gender (N/F) & $58 / 42$ & \\
\hline Mean age (years) & 63 & $(35-91)$ \\
\hline Median follow-up (montlis) & 30 & \\
\hline $\begin{array}{l}\text { Histology } \\
\text { Adenomas }\end{array}$ & 71 & \\
\hline $\begin{array}{l}\text { Carcinomas } \\
\text { Carcinoids }\end{array}$ & 23 & \\
\hline $\begin{array}{l}\text { Solitary ulcer } \\
\text { Tumor distance from } \\
\text { anal verge (cm) }\end{array}$ & 5 & \\
\hline
\end{tabular}

demonstrated understaging of $\mathrm{T} 2$ tumour assessed as $\mathbf{T} 1$.

All cases were performed under general anaesthesia with intra-operative repositioning of the patient for efficient surgical access with the TEM rectoscope. According to the lesion location, patients were placed in 25 cases in a jacknife position, 18 in a right lateral decubitus, 15 in a left lateral decubitus and 42 in the lithotomy position. The average operation time was $98 \pm 24$ min.

Full-thickness resection (mucosa and serosa down to the perirectal fat) was performed in $94(94 \%)$ cases. In the remaining $6(6 \%)$ cases a mucosectomy was performed in order to avoid peritoneal entry. Adenomas were resected with a $0.5 \mathrm{~cm}$ safety margin; in cases of carcinoma the margin was at least $1 \mathrm{~cm}$. After ensuring haemostasis, the defect was closed by a 3-0 running suture in 92 cases. In the remaining 8 adenonacases, the defect, localized below the peritoneal reflection, was left open due to closure suture difficulties, without any postoperative morbidity. In 6 patients presenting with distal lesions, TEM resection was complemented with a conventional suture using a Park's retractor because of gas lost and impaired vision. 
In two cases, we decided to 'convert' intraoperatively to laparotony and low anterior rectal resection; the first one after tumonr removal due to closure difficulties of the peritoneum, and the second after endoscopic visualization before starting transanal resection. There were eight cases of inadvertent peritoneal entry $(8 / 100 ; 8 \%)$ associated with the resection of higl rectal adenomas. Two of these eight patients had a postoperative clinical and radiological pneumoperitoneum but no further therapy was necessary.

Wound breakdown was discovered postoperatively in 7 cases. In two of them, due to retrorectal abscess formation and sepsis, a diverting loop ileostony was performed. A third case in which we performed a loop ileostomy, developed a postoperative rectovaginal fistula. There was no mortality. The other 4 patients had no further complications and were managed with oral antibiotics and bowel confinement.

Immediate postoperative salvage therapy by means of low anterior rectum resection and total mesorectal excision (TME) was required in four cases (4\%) after assessing high-risk featmes (poor differentiation and/or lymphovascular invasion) in $\mathrm{T} I$ tumours $(n+3)$ or 'T2 $(n+1)$ invasion in the definitive histology study (Table 2 ). Definitive histopatlology after TME confirmed T1G2 $\mathrm{N} 0(n+3)$ and T2G2 No $(n+1)$ stages.

Median hospitalization was 5.5 days (range 3-21. days). A clinical examination was performed in all patients before hospital discharge.

Clinical assessment of sphincter function revealed continence impairnent in 68 patients during the finst three weeks after surgery. We did nol perform manonetric studies but only clinical assessment. Followup at three months showed that 98 patients had fully recovered. The two other's, with already impaired continence preoperatively, showed injury at the internal splincter on ultrasonnd examination with permanent incontinence for liquids and gas. The lesions were benign, tubulo-villons adenonas with well to moderately differentiated dysplasia, in $71(71 \%)$ cases, 9 of them presenting as recurrence following previous open transanal resection. Malignant lesions (adenocarcinoma) were found in $23(23 \%)$ subjects. The histological study showed 16 cases of p $\mathrm{Tl}$ low risk carcinoma and 5 cases of pT 1 highl risk tumour and 2 cases of $\mathrm{p} T 2$ invasion. As already mentioned in four cases salvage therapy was indicated. Two patients refused salvage therapy upon our recoumendation and underwent adjuvant chemoradiotherapy. Surgical palliation decided upon pre-operatively was the indication in the other patient presenting witlı a $\mathrm{T} 2$ adenocarcinoma. The rentaining pathology includes carcinoids in $5(5 \%)$ patients and a solitary rectal ulcer in 1 ( $1 \%$ ) case (Table 1 ).

Over the follow-up period of 30 months (range 6-54 months) the recurrence rate was $5 \%$. Four cases of adenomas and one case of 'Tl low risk carcinoma. All four adenomas recurrences were treated with a new TEM resection. The patient with the rectal carcinoma recurrence after three years, was managed by abdominoperineal resection (APR) after radiochemotherapy (Table 2). Definitive histopathology showing a TlG2 No tumour.

\section{Discussion}

Over the past decade our understanding of rectal tumorigenesis has advanced rapidly: the knowledge gained has strengthened the concept of the adenomacarcinoma sequence, and has reinforced the practice of excision and surveillance [1].

Benign rectal tumours that are not suitable for snare diathermy excision are often amenable to removal by the transanal route by means of anal retractors using the method of Parks. However, this nethod is linited to the lower thind of the rectum. In addition, it 
Table 2. Complications

\begin{tabular}{|lcc|}
\hline Results & $\begin{array}{c}\text { Adenomas } \\
(n=71)\end{array}$ & $\begin{array}{c}\text { Carcinomas } \\
(n=23)\end{array}$ \\
\hline Wound lreakdown & 7 & 0 \\
\hline Ileostomy & 3 & 0 \\
\hline \begin{tabular}{l} 
Postop. bleeding \\
\hline Pneumoperitoneum
\end{tabular} & 4 & 0 \\
\hline Convertion to laparotomy & 2 & 0 \\
\hline $\begin{array}{l}\text { Early salvage therapy by } \\
\text { TLME }\end{array}$ & 0 & 0 \\
\hline Local recurrence & 5 & 1 \\
\hline Resection with TEM & 5 & 0 \\
\hline Resection with APR & 0 & 1 \\
\hline
\end{tabular}

may be difficult to visualize the nrargins of flat adenomas. Conventional managenient of higher rectal lesions usually involves transabdominal procedures, posterior transsacral (Kraske), or sphincter-splitting (YorkMason) approaclies. However, these are najor surgical procedures with associated complications and may be unsuitable and unnecessary if the purpose of the intervention is to resect benign lesions or low risk carcinomas [11].

With the developnent of TEM by Buess $e t$ al. [2], it is now possible to carry out formal transanal resection by means of a rectoscope, which affords excellent access and vision in the entire rectum. As a minimally invasive technique, TEM might be expected not only to benefit a small, specific population of patients in terms of morbidity but also to improve results in terms of completeness of excision and recurrence rates when compared to conventional transanal resection.

A full-thickness resection, as performed in almost all of our patients $(94 \%)$, is recommended to ensure an appropriate margin of safety. In addition, we found that this standard procedure is technically easier to perform than mucosectomy and that it decreases the risk of missing a small rectal cancer that may be located inside the villous adenoma. Such 'intraephitelial neoplasia / dysplasia' or 'early invasion' has been reported in up to $31 \%$ of cases [12]. Although it is often difficult to be sure about the precise techniques (full-thickness or submucosal) used, the rates of complete excision at the time of operation and the exact follow up, large published series report a rate of recurrences in up to $27.3 \%$ after transanal excision of rectal adenomas [13]. In contrast the results reported using TEM show a recurrence rate between 3 and $7 \%[3,4,7,14]$ with the $5.6 \%$ for the adenona cases of the present series being well in accordance witl previous studies. The overall norbidity rate for conventional transanal surgery in reported series varies from 0 to $14.5 \%$ [13], compared with $6 \%$ reported in the largest series of a total of 31.8 adenomas treated by Mentges et al. [3]. Thcse results are in accordance with others TEM-series reporting morbidity of up to $4.5 \%$ in nore than seven hundred patients $[4,7,14-16]$ and with the present study $(7 \%)$. It is of interest that postoperative bleeding is unusual with TEM, whereas it accounts for over hall of the complications reported in other series [13]. Peritoneal entry, on the other hand, as assessed intra-operatively in 8 patient (two of them with postoperative pnenmoperitoneum) of our present experience, can be a significant source of morbidity with TEM. Presumably the excellent vision afforded by TEM allows more precise haemostasis, whereas the ability to excise high rectal lesions increases the likelihood of peritoneal entry, especially when the tunour is anterior, and thus more likely to be above the peritoneal reflection. In our experience all perforations were recognized and managed by immediate endorectal suture.

Our results with TEM indicate that this technique is reproducible with suitable surgical training. Interestingly all three protective ileostomies in our series occurred within the first 20 cases indicating a learning curve despite the fact 
that all surgeons received a special TEM training.

Regarding the effect of a prolonged anal dilatation with the $4.0 \mathrm{~nm}$ dianeter TEM operative rectoscope, manometric studies indicate a decrease in anal sphincter tone ranging from $25 \%$ to $37 \%$ of pre-operative sphincter pressure, with recovery to clinical continence within 6-16 weeks [17-19]. We observed postoperative transitory grade II incontinence in 65 of the 100 patients, with full recovery in $98 \%$ of the patients after 12 weeks. There is also evidence indicating a significantly increased risk of lowering the anal resting pressurc by procedures lasting more than two hours [20]. Others found $21 \%$ disturbances of rectoanal coordination and rectal perception depending to the extent and type of resection of the tumour [21]. However, when making continence judgement, consideration would need to be given to the risk of incontinence by using the Parks retractor in conventional surgery [22], or after a low restorative rectal excision, if those were to be the alternative procedures.

To date, TEM has been used mainly for excision of sessile adenomas, and the experience with rectal cancers is limited. However, if tumours are carefully selected treatment of rectal cancer by TEM is generally accepted for so-called early low risk cancer [3]. The recurrence rate following this procedure lies between $4 \%$ and $8 \%[3,8,16,23]$ compared with a local recurrence rate of up to $30 \%$ for Tl high risk cancer [9].

The primary factor limiting the effectiveness of local treatment of early rectal cancer is lymph node invasion. The lymph node metastasis rate of TI rectal tumours occurs between $0 \%$ and $15.4 \%$, depending on different features $[9,24$, 25]. Other adverse factors in $\mathrm{T} l$ adenocarcinoma identified in the literature [26] are the following: gender, extensive budding, microacinar structures, depth of invasion in the submucosa, flat or depressed lesions, and location in the lower third of the rectum In our opinion and experience, positive excisional margins should not be regarded as a risk factor but should be viewed as an insufficient therapy which requires further treatment.

Therefore, careful patient selection is crucial to TEM outcome. Pre-operative staging must be precise and should be done by the surgeon himself. After clinical and endoscopy examination, assessment of histology including grading, and possible lymphovascular invasion, is mandatory. The tumour should be visualized with the rigid rectoscope to determine its distance from the dentate line and localize it precisely in the quadrant in order to plan the patient position for TEM and to avoid conversion to laparotomy due to size or localization. Endorectal sonography has always to be performed in order to assess depth of infiltration and lympli node invasion. Such precise staging is reportedly possible with an accuracy of up to $93 \%$ with respect to depth invasion and up to $81 \%$ for lymph node involvement $[27,28]$. In the present study, pre-operative endosonography staging was incorrect in only one T2-carcinoma case (understage as uT1) of the 97 patients investigated.

Although the reported rate of recurrence for Tl cancers resected by TEM is between $3.8 \%$ and $13 \%$, follow-up and differentiation between low and high risk features are very variable among the series published [3-6,8,9,16,23,29]. Compared with a recurrence rate of up to $18 \%$ after conventional transanal surgery $[30,31]$ TEM seems to achieve hetter results in the local excision of selected rectal cancer. To date, the only published prospective, randomised study comprised 52 patients with Tl tumours treated by TEM or anterior resection [29]. There were no significant differences in group outcome: The 5-year survival was $96 \%$; the local recurrence rate was $4.1 \%$ for TEM and $0 \%$ for anterior resection; and the metastasis rate was $0 \%$ for TEM and $4.1 \%$ for anterior resection. These results suggest that TEM 
may offer some advantage relative to anterior resection for $\mathrm{Tl}$ rectal cancer, with similar oncological results [29].

Although adjuvant or neoadjuvant chemoradiotherapy seems to improve the prognosis after local excision, the indications for any kind of therapy following local resection of rectal cancer by TEM remain controversial. In fact, local treatment of rectal cancer is limited by the impossibility of removing the potentially positive lynph nodes, supporting the concept of adjuvant radiotherapy, cliemotherapy, or both to achieve local control of the lymph nodes. The already published reports on the combined effect of TEM resection for rectal cancer followed by radiotherapy appears to support such a benefit [23]. Prelininary results suggest its reliability, with an improved recurrence-free disease survival for irradiated patients with T2 carcinonas, similar to that obtained by conventional surgery [32]. However, except for T1 low grade tumours, there is currently scant evidence to recommend the use of TEM for curative trealment of rectal cancer, with or without adjuvant therapy.

The use of TEM for purely palliative treatment of rectal cancer is not recommended [14]. In our limited experience (one case), local resection of certain high risk tumours with TEM but without radiotherapy is possible for compromised patients or those who refuse a laparotony. However, only a few reports confirm this use of TEM, with a local eomplication rate of $14 \%[6,23,33]$.

Because they are based on currently published indications and criteria for patient selection, our findings, both for adenomas and carcinomas, suggest that these standards remain adequate for identifying appropriate surgical candidates for TEM.

P. Palma, S. Freudenberg, S. Samel and S. Post, Department of Surgery, University Clinic, Mannheim, Germany.

\section{References}

1. Lestak $A$, Carey FA, Pratt NR, Steele RJC. The eolorectal adenoma-carcinoma sequence. Rev BrJ Surg 2002; 89: 84.5-60.

2. Bulss G, Hutrleren F, Theiss J, Böbel M, Issclanto W, Pichtmater H. Das System für dic transanale endoskopische Rectumoperation. Chirurg 1984; 55: 677-80.

3. Menteis B, Buess G, Schiner D, Manacke $K$ BECKER HD. Indications and results of local treatuent of rectal cancer. Dis Colon Rectum $1996 ; 39: 886-92$.

4. Steice: RJ, Hershan MJ, Mortensex NJ Armitage NC, Schomfredo JH. Thansanal endoscopic microsurgery - initial experience from three ecutres in the United Kingdom. $B r$ $J$ Surg 1996; 83: 207-10.

5. Sinter LE, Ko ST, Saclarides T, Causin P, ORKIN BA, KHANDUd KS. Transanal endoscopic microsurgery: initial registry results. Dis Colon Rectum 1996; 39: 79-84.
6. Lezocile E, Guerriert M, Pachines A Finlicioter F, Di Pilitrantonj F. Is Imansanal endoseopic microsurgery (TEM) a valid treatment for rectal tumors? Surg Endose 1996: 10: $736-4.1$.

7. Morescinit, M, Heint\% A, Bussmane M, Jungivger T. Followup after transanal endoscopic microsurgery or transanal excision of large benign rectal polyps. Langenbecks Arch Surg 1998; 383: 320-4.

8. Wind: G. Outcome following transanal endoscopic nicrosmrgery. Dis Colon Rectum 1998; 41: 526-31.

9. Heintz A, Morschel M, Jungingler T. Comparison of results after transanal endoscopic microsurgery and radical resection for 'T' carcinoma of the rectum. Surg Endosc $1998 ; 12: 1145-8$.

10. Di Gran: EJ, DoORnebosch PG, Sthssen LP, Demets JM, Trateroo GW, HoP WC. Transanal 
endoscopic microsurgery for rectal cancer, Eur $J$ Cancer 2002; 38: 904-10.

11. SENCUPTA S, TJANDRA JJ. Local excision of rectal cancer, What is the evidence. Dis Colon Rectum $2001 ; 44: 1345-61$.

12. Winbun GB. Surgical resection of villous adenonas of the rectum. Am Surg 1998; 64: $1170-6$.

13. SAKamoto GD, MacKelche JM, Senacore AJ. Transanal excision of large rectal villous adenomas. Dis Colon Rectum I991; 34: 880-5.

14. Snu S, S'Trpplit D. Transanal endoscopic microsurgrery in large, sessile adenomas of the rectum: a 10-year experience. Surg Endosc 1995; 9: $1106-12$.

15. Swanstiom LL, SMLLY P, Zilko J, CAgle L. Video endoscopic transanal-rectal tmmor excision. Am J Surg 1997; 173:383-8.

16. Saclarues TJ. Transaual endoseopic microsurgery: a single surgeou's experience. Arch Surg 1998; 133: 595-9.

17. HeMINGWAY D, Fle't' M, MoKeE RF, Finlay IG. Sphincler function after transanal endoscopic microsurgical excision of rectal tmmones. $\mathrm{Br} J$ Surg 1996; 83: 51-6.

18. KRELS ME, JEHLE EC, HALC; $V$ et al. Tunclional results after transanal endoscopic microsurgery. Dis Colon Rectum 1996; 39: $1116-20$.

19. BANERJEE AK, JeHle EC, KrEls ME et al. Prospeclive study of the proctographic and functional consequences of lransanal endoseopie microsurgery. Br J Surg 1996; 83 : $211-6$.

20. KENNEDY ML, LlBow'SKl DZ, KINC DW. Transanal endoscopic microsurgery excision. Is anorectal function compronised? Dis Colon Rectum 2002; 45: 601-1.

21. Herman RM, Richter P, Whlega P, Poplela T. Anorectal splincler finction and reclal barostat sludy in palients following transanal endoscopic microsurgery. Int $J$ Colorectal Dis $2001 ; 16: 370-6$.

22. VAN TETS WF, KIIJPERS JH, TRAN K, MOLLEN $R$, VAN Gour H. lnfluence of Parks anal retractor on anal sphineter pressures. Dis Colon Rectum 1997; 40: 1042-5.
23. Lezoche E, Guerrieri M, PMGANini AM, Feluciotrt F. Transanal endoscopic nicrosurgical excision of irradiated and nonirradiated rectal cancer: a 5-year experience. Surg Laparosendose 1998; 8: 249-56.

24. Morson BC. Histologrical criteria for local excision. Br J Surg 1985; 72 (Suppl.): 53-4.

25. Hermanek P, A. Pathologisl's point of view on endoscopically removed polyps of the colon and rectum. Acta Hepalogastroenterol 1978; 25 : $169-70$.

26. Naschmbexi R, Burgart IaJ, Nintruoncs S, LARSON DR. Risk of lymph node melaslasis in T I carcinoma of the colon and rectum. Dis Colon Rectum 2002; 45: 200-6.

27. Musom JW, Liveky IC, Stomel VM. 'The expanding ntility of endolnuinal ulirasonograpliy in the management of rectal cancer. Surgery 1992; 112: 832-41.

28. Massari M, De Simone M, Ciofe U, Rosso L, Chanela M, Gabrislal F. Value and limits of endorectal ultrasonography for preoperative staging of rectal carcinoma. Surg Laparosc Endosc 1998; 8: 438-43.

29. WiNul G, NotTbERc H, Keller R, SChMid KW, Buxte H. Surgical cure for early reclal calcinomas (T1): transanal endoscopic nicrosnrgery vs. anterior resection. Dis Colon Rectum 1996; 39: 969-75.

30. García Agular J, Melgoren A, Sirivongs P, But: D, MADofF RD. Rollumberger DA. Local excision of rectal cancer wilhout adjuvant lherapy: a word of caulion. Ann Surg 2000; 3: 345-51.

31. Madbouly KM, Renzt FH, Senagore Af, Fazlo VW, LAVERY IC. Recmrence after Irans-anal excision of T'l rechal cancer: Should we be concerned? Colorectal Dis 2002; 4 (Suppl I): 4.

32. Lezoche E, Guerrere M, Pagnix] AM, FELICIOT'T F Longlern results of palients will p'T2 rectal cancer treated will rodiotherapy and Iransanal endoscopic microsurgical excision. World J Surg 2002; 26: 1170-4.

33. Turder A, Scharek l, Pichlmater Il. Role of transanal endoscopic microsurgery in the palliative trealnent of rectal cancer: Scand J Gastroenterol 1997; 32: 58-64. 